\title{
miscellany
}

\section{Maytree - crisis intervention}

Maytree is a non-medical crisis intervention service for people who are suicidal and offers a brief stay of up to 4 nights at its attractively converted house in Finsbury Park, north London. It was founded by Paddy Bazeley and Michael Knight who have long experiences at the Samaritans and with time-limited psychotherapy. Its guests, accepted after careful assessment, are given ample opportunity to talk, in confidence and without fear or judgement, largely with volunteers trained in empathic listening, in a calm, safe, open and holistic environment. Maytree's core belief is that befriending and being heard in an environment of reciprocal trust improve selfesteem, relieve isolation and internal conflict, and rebuild the capacity to cope and, crucially, relate to others.

Guests leave with a goodbye letter which is intended to consolidate the benefits of the stay, and will typically restate (reformulate) the gains in self- understanding, the underlying 'core pain', the guest's rediscovery of (often forgotten) strengths, and remind the guest of emerging strategies to resolve or get through the factors precipitating the crisis. Finally, it offers some reflections on the healing and usually intense interpersonal experiences during the stay. A guest has no further recourse to Maytree and cannot stay a second time (although, importantly, help is given to set up sources of ongoing support), hence the goodbye letter may serve as a transitional object, enabling the stay to be internalised as a good ending - the exact opposite of suicide.

Maytree was recently evaluated by the Tavistock and Portman NHS Trust, who reported in June 2006 'a robust working model... [that] is effective, based on its therapeutic approach with clear boundaries'. They found a statistically significant reduction in distress levels from the clinical to the normal range among guests who stayed at Maytree over a 3-month period. Further, in follow-up interviews 3-5 months after their stay most guests had continued to improve and attributed this largely to the stay. The report concludes: 'Maytree makes a unique contribution to suicide prevention... there is a clear need for more centres based on the Maytree model'.

Since opening in late 2002 about 250 adults have stayed at Maytree, with numbers currently at 12 per month. Many others make contact and are befriended by phone or email, often coming for assessment and feeling better as a result of a lengthy talk or an offer of a stay, but defer taking up the offer.

Maytree is a charity, which receives no funding from the statutory sector and makes no charge to its guests who come from all parts of the UK.

For more information please visit the website at http://www. maytree.org.uk

Michael Knight Maytree Respite Centre, 72 Moray Road, Finsbury Park, London N4 3LG, email:mi.knight@ukonline.co.uk

doi: 10.1192/pb.bp.106.013847

\section{forthcoming events}

The European Society for Child and Adolescent Psychiatry (ESCAP) would like to announce Bridging the Gaps. Integrating Perspective in Child and Adolescent Mental Health, the 13th ESCAP International Congress which is to be held in Florence, Italy on 25-29 August 2007. The themes will include developmental neuroscience, assessment instruments, treatments and their effectiveness, and various other issues that will be addressed with reference to recent scientific developments. For further details please visit the ESCAP website at http:// www.escap-net.org

The International Association for the Scientific Study of Intellectual Disabilities (IASSID) would like to announce IASSID World Congress 2008, its 13th world congress, which will take place in Cape Town, South Africa on 25-30 August 2008. Delegates will include experts in all aspects of intellectual disabilities, including early childhood, health and social care services, physical and mental health, forensic issues and social policy. For further details please visit the IASSID website at http://www.iassid.org

doi: 10.1192/pb.bp.106.013854 